\title{
The evaluation of the effectiveness of the Functional Movement System concept in improving physical performance and reducing the pain of the Flying Personnel of the Polish Armed Forces \\ A - preparing concepts
}

$\mathrm{B}$ - formulating methods

$\mathrm{C}$ - conducting research

$\mathrm{D}$ - processing results

$\mathrm{E}$ - interpretation and conclusions

F - editing the final version

\author{
Aleksandra Stanek ${ }^{1, A-F}$, Arkadiusz Berwecki',A,C-F, Aneta Bac ${ }^{3, C-F}$, \\ Tomasz Ridan',E-F
}

${ }^{1}$ Military Training and Conditioning Center in Zakopane

${ }^{2}$ Department of Physiotherapy, Faculty of Rehabilitation, University of Physical Education in Krakow

${ }^{3}$ Department of Occupational Therapy, Faculty of Rehabilitation, University of Physical Education in Krakow

https://doi.org/10.5114/areh.2019.84187

Key words: pain, physical performance, FMS, pilots

\section{Introduction}

Flying personnel, especially the military one, consists of people characterized by high psychophysical predispositions and abilities to work in hard conditions. It is a profession reserved for a small group of people. Each type of aircraft has a different purpose, equipment and requires different handling. It can lead to a locomotive system's overload, typical of the given profession. An appropriate 
psycho-physical condition and a high resistance of the organism to various external influences is one of the conditions determining the proper performance of aviation tasks [1,2].

In order to be able to fulfill their duties, the flying personnel is covered by strictly regulated medical care provided by the military health service. The military health service provides health prevention, including physical rehabilitation. Physiotherapy of the flying personnel focuses not only on the biological aspects of rehabilitation but also on health and the increase of body's tolerance to physical stress. Rehabilitation can help these individuals acquire motor skills, improve their body's abilities and gain awareness of how to make use of the prophylaxis of injuries and overloads of the musculoskeletal system [1-4].

In order to be able to run a rehabilitation program successfully, the patient's motor skills should be assessed prior to the implementation of the program. The Functional Movement System (FMS) concept is one of the tools used for assessing motor skills. It is a simple screening tool that allows identification of multifaceted asymmetries between the body segments. The obtained results help to define general principles of a therapeutic treatment as well as to plan effective functional training exercises $[5,6]$. On the basis of a quick analysis we can find the weakest link in the kinematic chain, which is also the determinant of its strength. It leads to eliminating overloads and reducing the risk of injuries. There are two more advantages of this concept worth mentioning: it is easy to conduct and the evaluation of the progress after the therapy or training is simple as well. In addition, it is a safe evaluation system $[7,8]$.

The FMS is a functional evaluation system, which focuses on movement patterns and not on its elements. The tests focus on basic movements and positions that translate into complex motor activities. Thanks to proper instructions and attention to detail the testing system reveals asymmetry and significant limitations of mobility, stability and neuromuscular coordination. Then it indicates the directions for correcting the irregularities. Detecting kinematic chain disorders by detecting deficits and biomechanical disturbances also allows determination of injury risk. Since the ordinal scale $0-3$ is applied, the test enables comparison and reproducibility of the results [9-12].
Detection of kinematic chain disorders by detecting deficits and biomechanical disturbances also allows determination of injury risks, which result from many factors, as discussed in Bonazza et al. [13]. Among these factors there must be consideration of any previous body injuries, age, sex, the number of points obtained, asymmetries of the motion system as well as the type of the performed physical activity. The maximum possible number of points to get is 21 and with a smaller number the risk of injuries increases. Obtaining less than 14 points indicates a greater risk of injury, however, this applies to adults since younger age accounts for biological immaturity and natural inability to perform given tests properly [14-16]. A sensation of discomfort in the musculoskeletal system experienced during the test or suffering any pain resulting from a previous injury or the latest discomfort acquired at work or during a daily physical activity also reduce the efficiency of movement and increase the risk of injury $[17,18]$.

The FMS-based test consists of seven interrelated and equally important movement patterns. If the test is performed incorrectly, no abnormalities will be detected, and subsequently it may lead to a random selection of exercises and the lack of solution to the problem. Mobility, strength, flexibility, coordination and balance are essential for successful accomplishment of the test [11]. The first three FMS tests, referred to as functional movement patterns: deep squat, hurdle step and inline lunge illustrate the placement of feet in three basic positions taken by people while moving on a daily basis. The four other tests, referred to as fundamental movement patterns: active straight-leg raise, shoulder mobility, trunk stability push up and rotary stability, help to clarify the information and to show the degree of compensation in the main patterns. Moreover, they treat the left and right side of the body separately since faulty movement patterns can be caused by the existing asymmetry and vice versa - the asymmetry can result from a faulty posture. The FMS examines the basic effects of exercises and movements, therefore it is recommended to perform the test prior to starting training preparations or a physical activity $[7,10,12]$.

The aim of this work was to evaluate the application of the FMS concept in improving the mobility of the Flying Personnel of the Polish 
Armed Forces by comparing the results of the FMS test between the test and control groups. An attempt to compare the reduction of discomfort experienced in the FMS-based provocative tests was also undertaken.

\section{Material and methods}

The research was carried out at the Military Training and Conditioning Center in Zakopane and it lasted from July to December 2017. One hundredtwenty randomly selected male representatives of the Flying Personnel of the Polish Armed Forces aged 25 to $52(35.0 \pm 6.9)$ were examined. The research was conducted in accordance with the requirements of the Helsinki Declaration.
Tab. 1. The age profile of the analyzed groups

\begin{tabular}{|c|c|c|c|c|c|c|}
\hline & 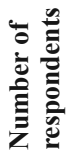 & 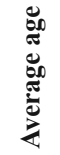 & 当 & $\underset{\mathrm{E}}{\mathrm{E}}$ & 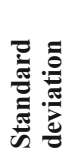 & Confidence interval \\
\hline Total & 120 & 35.5 & 25.0 & 52.0 & 6.9 & $\mathrm{P}\{34.3<\mathrm{m}<36.7\}=0.95$ \\
\hline $\begin{array}{l}\text { Study } \\
\text { group }\end{array}$ & 60 & 35.8 & 25.0 & 52.0 & 6.6 & $\mathrm{P}\{34.1<\mathrm{m}<37.5\}=0.95$ \\
\hline $\begin{array}{c}\text { Control } \\
\text { group }\end{array}$ & 60 & 35.3 & 26.0 & 52.0 & 7.2 & $\mathrm{P}\{33.5<\mathrm{m}<37.1\}=0.95$ \\
\hline
\end{tabular}

The study group consisted of helicopter, transport aircraft and high maneuverability aircraft pilots as well as flying engineers and parachute instructors. The examined persons were randomly assigned to two groups: a study group $(\mathrm{n}=60)$ and a control group $(\mathrm{n}=60)$ (Tables 1 , and 2).

Tab. 2. The age profile of individual groups

\begin{tabular}{|c|c|c|c|c|c|c|c|}
\hline & & $\begin{array}{l}\text { Number of } \\
\text { respondents }\end{array}$ & Average age & Minimum & Maximum & $\begin{array}{l}\text { Standard } \\
\text { deviation }\end{array}$ & Confidence interval \\
\hline \multirow{2}{*}{ Helicopter pilots } & Study group & 24 & 33.7 & 25.0 & 52.0 & 7.1 & $\mathrm{P}\{30.6<\mathrm{m}<36.8\}=0.95$ \\
\hline & Control group & 31 & 32.8 & 26.0 & 52.0 & 7.4 & $\mathrm{P}\{30.0<\mathrm{m}<35.6\}=0.95$ \\
\hline \multirow{2}{*}{ Transport aircraft pilots } & Study group & 7 & 30.0 & 25.0 & 35.0 & 5.0 & $\mathrm{P}\{25.0<\mathrm{m}<35.0\}=0.95$ \\
\hline & Control group & 7 & 39.0 & 31.0 & 47.0 & 11.3 & $\mathrm{P}\{27.7<\mathrm{m}<50.3\}=0.95$ \\
\hline \multirow{2}{*}{$\begin{array}{c}\text { High maneuverability aircraft } \\
\text { pilots }\end{array}$} & Study group & 3 & 34.3 & 27.0 & 42.0 & 5.4 & $\mathrm{P}\{17.9<\mathrm{m}<50.7\}=0.95$ \\
\hline & Control group & 2 & 36.0 & 28.0 & 47.0 & 6.4 & $\mathrm{P}\{16.5<\mathrm{m}<63.5\}=0.95$ \\
\hline \multirow{2}{*}{ Flying Engineers } & Study group & 13 & 40.3 & 29.0 & 47.0 & 5.4 & $\mathrm{P}\{36.9<\mathrm{m}<43.7\}=0.95$ \\
\hline & Control group & 17 & 38.6 & 28.0 & 46.0 & 6.1 & $\mathrm{P}\{35.2<\mathrm{m}<42.0\}=0.95$ \\
\hline \multirow{2}{*}{ Parachute instructors } & Study group & 13 & 37.2 & 31.0 & 50.0 & 5.6 & $\mathrm{P}\{33.7<\mathrm{m}<40.7\}=0.95$ \\
\hline & Control group & 3.0 & 37.7 & 35.0 & 43.0 & 4.6 & $\mathrm{P}\{23.7<\mathrm{m}<51.7\}=0.95$ \\
\hline
\end{tabular}

In both the test and control groups a standard training program was provided for the flying personnel as a part of the training and conditioning camp. In addition, the members of the study group participated in the original rehabilitation program based on the FMS concept. The program was conducted by a physiotherapist 12 times within 21 days of the training camp and each lasted 30 minutes. It consisted of exercises, selected adequately to the results obtained during the original test, in accordance with the FMS concept. The following factors were considered: asymmetries, disturbances of mobility and stability as well as an improper performance of global movement patterns. Close attention was paid, among others, to the improvement of neuromuscular coordination, mobility of the lumbo-pelvic-hip complex (LPH), peripheral joints, deep sensation and balance.

All members of the flying personnel who took part in the research, both from the study and control groups, underwent the FMS-based test twice.
The first measurement was conducted before the rehabilitation program started and the second after it was completed. The test took place under the same conditions, i.e. in the gym, without any warm-up and in a sports outfit.

The FMS test consisted of 7 exercises assessing movement patterns (deep squat, hurdle step, inline lunge, shoulder mobility, active straightleg raise, trunk stability push up and rotational stability movement pattern) and 3 pain provoking tests (subacromial space irritation test, back hyperextension lying face down, spine flexion in the so called "Child's pose") as well as the FMS protocol. The FMS testing tool consisted of a $5 \times 15 \times 150 \mathrm{~cm}$ base, a dowel with a centimeter scale, two crossbars with a centimeter scale and a flexible rubber band. Each exercise was performed 3 times. The tester assessed the best performance according to the established assessment criteria:

- 3 points - movement is done completely and without pain 
- 2 points - compensated movement pattern

- 1 point - inability to take the starting position or move

- 0 points - occurrence of pain during the movement If there were any doubts, the tester downgraded the assessment of the performance. In the case of asymmetric tests, the lower grade determined the final result of a given attempt. Each tested person could reach the maximum 21 points [10].

The collected data was analyzed using ANOVA in STATISTICA 13.1 software. To perform the calculations of the asymptotic significance value or p-value (p) we used the dependent (paired) sample t-Student, having determined the necessary assumptions about the normal distribution of differences beforehand. The level of significance was set at $\alpha=0.05$. The direction of the correlation was determined by the value of the r-Spearman correlation coefficient [19].

\section{Results}

The first tested variable was the result of the FMS test. In the first measurement, the highest average result was obtained by helicopter pilots in the test group, whereas in the control group the highest average score was obtained by the high maneuverability aircraft pilots. In the second measurement, the highest average score in the study group was obtained by helicopter pilots and in the control group by the high maneuverability aircraft pilots. A statistically significant result at the significance level of $\mathrm{p} \leq 0.05$ was observed in the study group of helicopter pilots, deck technicians and parachute instructors (Table 3 ).

Tab. 3. An average FMS test score for both groups related to the type of work

\begin{tabular}{|l|c|c|c|c|c|c|}
\hline \multirow{2}{*}{\multicolumn{1}{|c|}{ Type of work }} & \multicolumn{2}{c|}{ Study group } & \multicolumn{2}{c|}{ Control group } & \\
\cline { 2 - 8 } & Test 1 & Test 2 & p & Test 1 & Test 2 & p \\
\hline Helicopter pilots & 14.9 & 16.7 & 0.003 & 14.8 & 15.2 & 0.516 \\
\hline Transport aircraft pilots & 13.7 & 15.2 & 0.199 & 14.1 & 14.0 & 0.885 \\
\hline High maneuverability aircraft pilots & 14.3 & 15.7 & 0.230 & 15.0 & 17.0 & 0.293 \\
\hline Flying Engineers & 13.0 & 14.6 & 0.045 & 14.8 & 14.9 & 0.854 \\
\hline Parachute instructors & 14.4 & 16.5 & 0.018 & 14.7 & 14.3 & 0.900 \\
\hline
\end{tabular}

* Statistical significance $\mathrm{p} \leq 0,05$

Differences in the FMS test for both groups were studied before the project started and after it finished. A statistically significant difference (improvement of the result) was attained only by the persons from the study group (Tab.4.).

Tab. 4. Analysis of differences in the FMS test results before and after a series of exercises

\begin{tabular}{|c|c|c|c|c|c|c|c|}
\hline & & Average & Min. & Max. & SD & Confidence interval & $\mathbf{p}$ \\
\hline \multirow{2}{*}{ Study group } & Test 1 & 14.2 & 9.0 & 19.0 & 2.2 & $\mathrm{P}\{13.6<\mathrm{m}<14.8\}=0.95$ & \multirow{2}{*}{0.0001} \\
\hline & Test 2 & 16.0 & 11.0 & 19.0 & 2.0 & $\mathrm{P}\{15.5<\mathrm{m}<16.5\}=0.95$ & \\
\hline \multirow{2}{*}{ Control group } & Test 1 & 14.8 & 11.0 & 18.0 & 1.8 & $\mathrm{P}\{14.3<\mathrm{m}<15.3\}=0.95$ & \multirow{2}{*}{0.19} \\
\hline & Test 2 & 15.0 & 11.0 & 18.0 & 2.0 & $\mathrm{P}\{14.5<\mathrm{m}<15.5\}=0.95$ & \\
\hline
\end{tabular}

The second indicator examined was discomfort experienced in the lumbar or cervical spine during the tests provoking pain symptoms in the studied men. The study group reported significant pain experience in the first measurement, and its absence in the second measurement. In the control group, the discomfort felt in some cases appeared in the re-measurement, despite its lack in the first measurement. The first measurement revealed that in both groups it was helicopter pilots who complained the most frequently about the physical problems. In the second measurement, the occurrence of the ailments was most often reported by the parachute instructors both in the study and control groups (Table 5).

Tab. 5. Percentage distribution of the occurrence of discomfort and pain symptoms in both groups depending on the type of work

\begin{tabular}{|l|c|c|c|c|}
\hline \multirow{2}{*}{\multicolumn{1}{|c|}{ Type of work }} & \multicolumn{2}{c|}{ Study group } & \multicolumn{2}{c|}{ Control group } \\
\cline { 2 - 5 } & Test 1 & Test 2 & Test 1 & Test 2 \\
\hline Helicopter pilots & $41.7 \%$ & $0 \%$ & $12.9 \%$ & $6.5 \%$ \\
\hline Transport aircraft pilots & $28.6 \%$ & $0 \%$ & $0 \%$ & $14.29 \%$ \\
\hline High maneuverability aircraft pilots & $33.3 \%$ & $0 \%$ & $0 \%$ & $0 \%$ \\
\hline Flying Engineers & $7.7 \%$ & $0 \%$ & $5.9 \%$ & $5.9 \%$ \\
\hline Parachute instructors & $38.5 \%$ & $7.7 \%$ & $0 \%$ & $33.3 \%$ \\
\hline
\end{tabular}


In the first and second test in both groups there was also examined a relationship between the occurrence of discomfort and selected variables such as a type of work and age. A statistically significant relationship was observed between the performed work and pain occurrence in the study group, whereas in the control group there was noticed a relationship between the age and the discomfort experienced (Table 6).

Tab. 6. Analysis of the relationship between the occurrence of discomfort and pain symptoms and selected variables for both groups

\begin{tabular}{|l|l|l|c|}
\hline & & \multicolumn{1}{|c|}{ Variable } & p \\
\hline \multirow{4}{*}{ Study group } & \multirow{2}{*}{ Test 1} & Performed work vs. occurrence of pain & 0.043 \\
\cline { 3 - 4 } & & Age vs. occurrence of pain & 0.261 \\
\cline { 2 - 4 } & \multirow{2}{*}{ Test 2} & Performed work vs. occurrence of pain & 0.265 \\
\cline { 3 - 4 } & & Age vs. occurrence of pain & 0.907 \\
\hline \multirow{3}{*}{ Tontrol group } & \multirow{2}{*}{ Test 1 } & Performed work vs. occurrence of pain & 0.358 \\
\cline { 2 - 4 } & & Age vs. occurrence of pain & 0.024 \\
\cline { 2 - 4 } & \multirow{2}{*}{ Test 2 } & Performed work vs. occurrence of pain & 0.472 \\
\cline { 2 - 4 } & & Age vs. occurrence of pain & 0.496 \\
\hline
\end{tabular}

* Statistical significance $\mathrm{p} \leq 0,05$

\section{Discussion}

Physical fitness is reflected in the ability to perform and solve motor tasks in situations requiring speed, agility, flexibility, strength and endurance. Having a high level of general fitness is an essential attribute for soldiers to have in order to show flexibility in every situation during war operations. The key elements are mobility, flexibility, strength and endurance. In Poland, at present only Szarska et al. [20] conducted the FMS surveys among professional soldiers of the Polish Armed Forces demonstrating that the large spread in the assessment of the movement pattern indicates the presence of diverse irregularities within the studied group [21,22].

The presented research showed a statistically significant difference both between the first and second test in the study group as well as between the entire study and control group after completing a full cycle of motor rehabilitation. This confirms that the implemented movement program translates into an improvement in the quality of the movement of the flying personnel of the Polish Armed Forces.

The particularly common musculoskeletal injuries reduce the productivity of soldiers, as confirmed by Cohen et al. [23]. They claimed that the injuries to the musculoskeletal system accounted for $24 \%$ of all injuries of the military personnel serving in Iraq and Afghanistan. Bodden et al. [24] developed in their program a series of corrective exercises for those who received less than 14 points in the FMS test and those with a significant asymmetry. The re-examination showed the correction of the asymmetry and incorrect patterns, which translated into a higher score and a reduced risk of injuries. The 4-weeks-long correction program brought significant improvement to the test results. Goss et al. [25] planned and conducted a special 6-weekslong program aimed at improving the physical fitness of 90 soldiers of special forces. A training unit also included injury prevention exercises that were aimed at improving posture control, stability, mobility and neuromuscular coordination. The value of the FMS test increased by an average of 2.5 points after the whole workout cycle. Frost et al. [5] having conducted the FMS test in a group of 60 firefighters in active service for the purpose of their research, introduced a 12 -weeks training program. The results showed an improvement in the quality of movement for 26 examined persons. Furthermore, in the conclusions they highlighted the fact that the quality of performance in the tests translated into the quality of fulfilling their daily activities.

Our study showed a statistically significant difference between the first and the second test for the study group. Each group of the flying personnel increased the average number of points. The greatest improvement was noted for helicopter pilots, parachute instructors and on-board technicians for whom the change in results was statistically significant. In the control group the average score did not change. Although some individuals received a higher score, it was not statistically significant. It was just the high maneuverability aircraft pilots who increased the average number of points. It means that additional motor functions improvement, introduced next to the classic training, proved to be more effective in improving motor skills assessed 
with the FMS test. It is assumed that a result below 14 points increases injury risk significantly [11]. It can therefore be assumed that the improvement of motor skills will affect prophylaxis and reduce injury risk.

Musculoskeletal pains occur very early in pilots due to the effects of acceleration, vibration and staying for a long time in a forced position in the airplane seat with an incorrect position of the head, which is additionally loaded by a heavy helmet during the flight. It increases the activity of paraspinal muscles, causes muscular disbalance and leads to micro injuries of the musculoskeletal system, which in consequence causes changes in shoulder girdle such as restricted mobility and experiencing discomfort. According to Klukowski and Kurek [1], lower back pain occurs periodically in $20 \%$ of pilots regardless of the type of the aircraft. The reason for about $50 \%$ of hospitalizations of the flying personnel in the WIML Psychoneurological Clinic is pain in the lumbar region of the spine. According to the authors, it occurs much more often by over 7.5 flight-hours a day, and 40-50 flight-hours per month. It is worth noting the impact of acceleration on a pilot's body. Accelerations act along the vertical axis of the body causing blood to flow to the lower parts of the body. The blood moves in the opposite direction to the performed maneuvers, which can be prevented by an appropriate muscle tension aimed to stop the outflow of blood from the head. Therefore pilots suffer from the reflexive isometric muscle contraction of the skeletal muscles with the tightening of the lumen of the blood vessels, which is extremely stressful for muscles $[1,2]$. The statistically significant relationship between the work performed and pain as well as between age and discomfort may indicate that an incorrect forced position when performing work duties negatively affects the musculoskeletal system and leads to overloading of the musculoskeletal system. At the same time, older age is associated with more seniority which may be connected with a more frequent sensation of discomfort. When analyzing the position of transport aircraft pilots, it should be noted that the asymmetry of the shoulder girdle may be associated with their function during the flight. The commander acting as the first pilot occupies the position on the left side of the cabin and he has left shoulder girdle extended in protraction during the entire flight to have his hands on the yoke. Similarly, the second pilot has overstrained muscles in the right shoulder girdle. In addition, more advanced age is associated with longer work experience, and thus the overload of the movement system. Stępnik and Czaprowski [26] believe that neck pain is one of the most frequent reasons to visit a physiotherapist, while Czajka and colleagues [27] note that lumbar spine ailments affect up to $80 \%$ of adults.

In our research it was found that in the study group people from each profession reported discomfort in the movement system during the first measurement. Helicopter pilots and parachute instructors experienced pain the most frequently, whereas it was the rarest for deck technicians. In the re-measurement In the re-measurement only few parachute instructors felt ailments, whereas for the rest of the examined persons there was observed a complete reduction of pain. Analyzing the control group, the emerging discomfort and pain in the first measurement were reported only by helicopter pilots and deck technicians, however, the reduction of these ailments did not occur in all of the cases. It was only the high maneuverability aircraft pilots who did not express any discomfort in both measurements. The representatives of the other studied professions did not complain about any discomfort in the first measurement, but it did occur in the second measurement.

In a study by Goss et al. [25], it was noticed that the reduction of back pain, especially in people obliged to wear heavy vests, contributed, among others, to improvement of stability. A functional training program was aimed at the soldiers who returned to service after suffering injury to the musculoskeletal system. The observed results confirmed a safe and effective way to increase mobility. What is more, the functional training can be conducted in a way that reflects the specific type of work performed by the soldiers, paying attention to the most frequently used plane of motion [23].

In our own research it was found that all the persons from the study group suffered from pain during the first measurement. Helicopter pilots and parachute instructors experienced pain the most frequently, whereas it was the rarest for flying engineers. In the re-measurement it was a very small number of parachute instructors who felt pain, whereas for the rest of the examined persons there was observed a complete reduction of pain. When analyzing the control group, in the first measurement pain symptoms were reported only by helicopter pilots and flying engineers, however, the 
pain was not reduced in all the cases. It was only the high maneuverability aircraft pilots who did not express any discomfort in both measurements. Representatives of the other studied professions did not complain about any pain in the first measurement, but it did occur in the second measurement.

In the treatment of spinal pain, it is effective to combine different forms of therapy, such as massage, stabilization exercises, stretching exercises, manual therapy, the McKenzie method, osteopathic techniques. The analysis of the literature allows the conclusion that the common denominator of the applied treatment methods is an appropriately adjusted to the patient's needs form of movement. Proper physical activity improves quality of life both in the physical and mental spheres as well as influences the delay of aging processes and related consequences, such as motor system damage. It is necessary to develop effective and reproducible treatment methods of these ailments also due to the high costs of treatment incurred by the state budget [26-28].

As supported by the literature on this subject, motor stereotype disorders may result from both structural and functional disorders. Both our own research, as well as the literature of the subject demonstrate that it is possible to influence the formation of the correct motor patterns through a properly selected exercise program. The quality of movement depends on many factors, not only those on which the individuals have influence but also those resulting from their work. Flying personnel should apply both strength and endurance trainings as well as general improvement and specialized exercises that consider individual needs. This process requires the cooperation of flying personnel and people planning flights with physiotherapists, physical education instructors and doctors. Therefore, a comprehensive physical training program should be accompanied by motor and functional improvement exercises [12,20,22,5,29].

\section{Conclusions}

The improvement program containing elements of the FMS concept significantly improved the functional fitness of the studied flying personnel. Moreover, the percentage of people experiencing spinal pain decreased as a result of the therapy which included the elements of the FMS concept.

\section{References}

1. Klukowski K, Kurek Z. Odnowa biologiczna pilotów - moda czy konieczność? Fizjoter. 2009;17(3):56-61.

2. Skrzypkowski A. Medycyna Lotnicza. Fizjologia i trening lotniczy. Warszawa: WIML; 2012.p.212-230,319-47.

3. Regulamin Kultury Fizycznej Sił Zbrojnych RP. Szkol. 842/2011.

4. Ustawa o sporcie z dnia 25 czerwca 2010r. (Dz.U. Nr 127, poz.857).

5. Frost DM, Beach TA, Callaghan JP, McGill. Using the Functional Movement Screen to evaluate the effectiveness of training. J Strength Cond Res. 2012;26(6):1620-30.

6. Wright MD, Portas MD, Evans VJ, Weston M. The Effectiveness of 4 Weeks of Fundamental Movement Training on Functional Movement Screen and Physiological Performance in Physically Active Children. J Strength Cond Res. 2015;29(1): 254-61.

7. Cook G, Burton L, Hoogenboom B. Pre-Participation Screening: The Use of Fundamental Movements as an Assessment of Function - Part 1. N Am J Sports Phys Ther. 2006;1(2):62-72.

8. Lemiesz G, Iwańczyk K, Biernat R, Godlewski J, Szymański M, Biernat U. Zastosowanie Testu Funkcjonalnej Oceny w Praktyce. 2013;39:46-9.

9. Kochański B, Plaskiewicz A, Kałużny K, Dylewska M, Płoszaj O, Hagner-Derengowska M, et al. Functional Movement Screen(FMS) - kompleksowy system oceny funkcjonalnej pacjetna. = Functional Movement Screen (FMS) - a comprehensive system for the functional evaluation of the patient. J Edu Health Sport. 2015;5(4):90-101.

10. Cook G, Burton L, Hoogenboom B. Pre-Participation Screening: The Use of Fundamental Movements as an Assessment of Function - Part 2. N Am J Sports Phys Ther. 2006;1(3):132-9.

11. Kiesel K, Plisky PJ, Voight ML. Can Serious Injury in Professional Football be Predicted by a Preseason Functional Movement Screen? N Am J Sports Phys Ther. 2007;2(3):147-58.

12. Cook G. Movement. Functional Movement System. Screening-Assessment-Corrective Strategies. Santa Cruz, California; 2015.

13. Bonazza NA, Smuin D, Onks CA, Silvis ML, Dhawan A. Reliability, Validity, and Injury Predictive Value of the Functional Movement Screen. A Systematic Review and Meta-analysis. Am J Sports Med. 2017;45(3):725-32.

14. Chalmers, S Fuller J, Debenedictis T, Townsley S, Lynagh M, Gleeson C, et al. Asymmetry during preseason Functional Movement Screen testing is associated with injury during a junior Australian football season. J Sci Med Sport. 2017;20(7): 653-7. 
15. Chorba RS, Chorba DJ, Bouillon LE, Overmyer CA, Landis JA. Use of a Functional Movement Screening tool to determine injury risk in female collegiate athletes. NAJSPT. 2010;5(2):47-54.

16. Duke SR, Martin SE, Gaul CA. Preseason Functional Movement Screen predicts risk of time-loss injury in experienced male rugby union athletes. J Strength Cond Res. 2017;31(10): 2740-7.

17. Bushman TT, Grier TL, Canham-Chervak MC, Anderson MK, North WJ, Jones BH. Pain on Functional Movement Screen Tests and Injury Risk. J Strength Cond Res. 2015;29(11):65-70.

18. Fuller JT, Chalmers S, Debenedictis TA, Townsley S, Lynagh M, Gleeson C, et al. High prevalence of dysfunctional, asymmetrical, and painful movement in elite junior Australian Football players assessed using the Functional Movement Screen. J Sci Med Sport. 2017;20(2): 134-8.

19. Watała C. Biostatystyka. Bielsko Biała: Alfa Medica Press; 2012.

20. Szarska E, Maculewicz E, Rzepka R, Szynkolewska A. Zastosowanie testu FMS (Functional Movement Screen) do oceny wzorca ruchu żołnierzy rożnych rodzajów Sił Zbrojnych RP: badanie pilotażowe. Lekarz wojskowy. 2017;95(1):59-63.

21. Osiński W. Antropomotoryka. Poznań: AWF Poznań; 2003.

22. Heinrich KM, Spencer V, Fehl N. Carlos Poston WS. Mission essential fitness: comparison of functional circuit training to traditional Army physical training for active duty military. Mil Med. 2012;177(10):1125-30.

23. Cohen SP, Brown C, Kurihara C, Plunkett A, Nguyen C, Strassels SA. Diagnoses and factors associated with medical evacuation and return to duty for service members participating in Operation Iraqi Freedom or Operation Enduring Freedom: a prospective cohort study. Lancet. 2010;375(9711):301-9.

24. Bodden JG, Needham RA, Nachiappan Ch. The Effect of an Intervention Program on Functional Movement Screen Test Scores in Mixed Martial Arts Athletes. J Strength Cond Res. 2015;29(1):219-25.

25. Goss DL, Christopher GE, Faulk RT, Moore J. Functional training program bridges rehabilitation and return to duty. J Spec Oper Med. 2009;9(2):29-48.

26. Stępnik JH, Czaprowski D. Assessment of the effects of manual techniques on neck pain. Adv Rehab. 2018;2:33-9.

27. Czajka M, Truszczyńska-Baszak A, Kowalczyk M. The effectiveness of McKenzie Method in diagnosis and treatment of low back pain - a literature review. Adv Rehab. 2018;1:5-11.

28. Wołoszyn N, Wiśniowska-Szurlej A, Sozański B. An assessment of the relationship between the level of physical activity and the risk of falls and depression in elderly adults aged 60-75 years from the Podkarpackie region. Adv Rehab. 2018;2:41-8.

29. Minick KI, Kiesel KB, Burton L, Taylor A, Plisky P, Butler RJ. Interrater Reliability of the Gunctional Movement Screen. J Strength Cond Res. 2010;24(2):479-86. 